\title{
A complexidade da Atenção Psicossocial na Atenção Primária à Saúde: experiências formativas
}

\author{
The complexity of Psychosocial Attention in Primary Health \\ Care: formative experiences
}

\section{Willian Santos}

Universidade Federal do Recôncavo. Santo Antônio de Jesus, Bahia, Brasil. ORCID: 0000-0003-3224-3800.williantito@yahoo.com.br

RESUMO I INTRODUÇÃO: Este artigo relata uma experiência de estágio supervisionado desenvolvido no âmbito da graduação em Psicologia em uma universidade pública do interior da Bahia. OBJETIVOS: Esta experiência objetivou que os estagiários vivenciassem a complexidade da Atenção Psicossocial a partir de uma imersão real e efetiva na Atenção Primária à Saúde. MÉTODO: Os estagiários viviam durante um semestre a lógica de uma atuação interprofissional, compondo projetos de intervenção para atuar em Unidades de Saúde da Família, mas também fazendo interface com outros níveis de densidade tecnológica do Sistema Único de Saúde e com outras políticas setoriais, tais como a Assistência Social e a Educação. RESULTADOS E DISCUSSÃO: Este estágio, vivido principalmente através de atividades em grupo, atividades de sala de espera, atendimentos individuais, visitas domiciliares e interconsultas, convocou os discentes a lidarem com situações bastante desafiadoras para a Psicologia: compreender os determinantes sociais envolvidos nos processos de saúde-doença; a necessidade do trabalho multi/interprofissional efetivo, a articulação com a Rede de Atenção à Saúde/Psicossocial, entre outros aspectos. CONSIDERAÇÕES FINAIS: A inserção da Psicologia na Atenção Primária à Saúde deve se pautar na capacidade de ler o contexto das necessidades sociais e de saúde da população para pensar o tipo de cuidado que esta necessita. Faz-se necessário que a Psicologia e seus profissionais ultrapassem as barreiras de uma identidade profissional arraigada no saber biomédico e encontre uma prática e um comprometimento ético-político que cuide do usuário de forma integral e humanizada.

PALAVRAS-CHAVE: Atenção primária à saúde. Saúde mental. Serviços de saúde mental. Assistência ao paciente.

\begin{abstract}
INTRODUCTION: This article reports a supervised internship experience developed within the scope of Psychology in a public university in the interior of Bahia. OBJECTIVE: This internship aimed giving to the trainees experiencing the complexity of Psychosocial Care from a real and effective immersion in Primary Health Care. METHOD: The trainees lived during a semester the logic of an interprofessional work, composing intervention projects to act in Family Health Centers, but also interfacing with other levels of technological density of the Public Health System and other sectorial policies, such as Social Assistance and Education. RESULTS AND DISCUSSION: This stage, lived mainly through group activities, waiting room activities, individual visits, home visits and interconsultations, invited the students to deal with very challenging situations for Psychology: to understand the social determinants involved in the processes of health-disease; the need for effective multi/interprofessional work, articulation with the Network of Health Care/Psychosocial, among other aspects. FINAL CONSIDERATIONS: The insertion of Psychology in Primary Health Care should be based on the ability to read the context of the social and health needs of the population to think about the type of care it needs. It is necessary that Psychology and its professionals overcome the barriers of a professional identity rooted in biomedical knowledge and find a practice and an ethical-political commitment that takes care of the person in an integral and humanized way.
\end{abstract}

KEYWORDS: Primary health care. Mental health. Mental health services. Health assistance. 
Introdução

A entrada dos profissionais da Psicologia no campo das políticas de saúde guarda estreita relação com os rumos da Reforma Sanitária e, principalmente, da Reforma Psiquiátrica Brasileira a partir de meados dos anos 1970 e no decorrer da década de 1980 (Spink, 2007; Dimenstein, 2013). Decorrente diretamente das concepções e luta destas duas Reformas no campo da Saúde, o Sistema Único de Saúde (SUS) a partir de 1990 vai se consolidando enquanto uma política de Estado estruturada e aos poucos vai se configurando como um espaço importante de prática, formação e referência profissional para os psicólogos e psicólogas do Brasil (Spink, 2007).

A Reforma Psiquiátrica Brasileira (RPB), especificamente, foi um movimento articulado por usuários, familiares, trabalhadores e pesquisadores da saúde, pensando e reivindicando paulatinamente a meIhoria da assistência no campo ampliado da Saúde Mental. A RPB propôs a oferta de tratamento para os portadores de sofrimento psíquico em serviços de base comunitária, dispondo sobre a proteção e os direitos destes usuários e reivindicando a extinção progressiva dos hospitais psiquiátricos.

A partir da luta incansável do movimento da RPB, seus pressupostos vão sendo aos poucos colocados em prática, implicando, ainda nos anos 1980 e 1990, no desenvolvimento de algumas experiências de serviços e dispositivos em Saúde Mental em alguns municípios brasileiros. A partir de 2001 vai se estruturando uma política pública de Saúde Mental, principalmente através da implantação e capilarização paulatina dos Centros de Atenção Psicossocial (CAPS). Atuando inicialmente no nível especializado de atenção à Saúde Mental, é principalmente nestes serviços de saúde que a entrada da Psicologia se fez presente de forma mais vigorosa nos serviços públicos de saúde (Dimenstein, 2013).

O profissional da Psicologia passou, a partir daí, a ser considerado um trabalhador da saúde capaz de contribuir com a assistência e a promoção da Saúde Mental, já que, em tese, teria acesso a um arsenal teórico-técnico útil para ser utilizado com usuários em situações de potencial desenvolvimento de transtornos mentais (Dimenstein, 2013).
Com a criação paulatina de serviços e terapêuticas alternativas ao modelo asilar de tratamento, vemos a partir dos anos 2000 uma entrada cada vez maior dos profissionais da Psicologia nos programas de Saúde Mental em todo o Brasil. Neste período as políticas de Saúde Mental são continuamente avaliadas e se preconiza a necessidade do estabelecimento de Redes de Atenção Psicossocial (RAPS) para $\circ$ aprofundamento da Reforma Psiquiátrica, onde as ações pudessem se expandir para outros níveis de densidade tecnológica do SUS e se interconectar com outros saberes, práticas e categorias profissionais. Para haver este aprofundamento, o Ministério da Saúde do Brasil e diversos pesquisadores (Ministério da Saúde, 2014, Paulon \& Neves, 2013) apontam a necessidade de se investir no aumento das ações em Saúde Mental principalmente na Atenção Primária à Saúde (APS), considerando sua grande capilaridade nos territórios, sua proximidade com as famílias e usuários e por propor um cuidado longitudinal e integral.

\section{A especificidade da Atenção Primária à Saúde}

O interesse pela APS tem sido crescente nas políticas de saúde no Brasil e no mundo nos últimos anos. Esse interesse advém em grande parte do fato de que a APS tem sido considerada (por governos e especialistas) como porta de entrada e coordenadora dos sistemas públicos de Saúde, levando em consideração que este nível de densidade tecnológica se encontra próximo dos usuários e de suas famílias, tendo o potencial para resolver a maior parte dos problemas de saúde (Aquino, Medina, Nunes \& Sousa, 2014).

Apesar da discussão sobre a APS como coordenadora dos cuidados em saúde já ser bastante antiga (Mello, Fontanella \& Demarzo, 2009), no Brasil é apenas nos anos 1990, principalmente com a implantação do Programa de Saúde da Família a partir de 1994 (mais tarde denominado Estratégia de Saúde da Família - ESF), que a APS vai ser paulatinamente estruturada como uma política de envergadura nacional.

Até 2016 as duas últimas Políticas Nacionais da Atenção Básica (PNAB) (Ministério da Saúde, 2006; 2011 ) tinham na ESF sua estratégia prioritária para 
expansão e consolidação da APS e se apoiavam em uma proposta de transformação da realidade, com base no planejamento territorial, na ampliação dos mecanismos de participação social, na oferta de ações e serviços que visassem à inclusão e integração das populações vulneráveis e em situação de injustiça social. Sua atuação era entendida pelos diversos níveis de governo como prioritária para a reorganização do modelo de atenção à saúde no SUS, com uma ampla e complexa capilaridade nos mais diversos territórios, tendo adquirido legitimidade institucional junto à população brasileira (Aquino, Medina, Nunes \& Sousa, 2014).

No final de 2017 uma nova Política Nacional de Atenção Básica é implementada (Ministério da Saúde, 2017), promovendo amplos retrocessos na Atenção Primária do Brasil, a partir do momento em que relativiza a cobertura universal, não entende mais a ESF como organizadora do modelo de atenção à saúde, admite possibilidades de serviços tradicionais e com uma atuação já desgastada, segmentando o acesso e recompondo as equipes de saúde e os processos de trabalho. Vemos, dessa for$\mathrm{ma}$, uma série de riscos para as conquistas históricas obtidas com o fortalecimento da Atenção Primária à Saúde no Brasil, em um momento de forte ascensão de uma ideologia neoliberal, onde as modificações propostas nesta "nova" política reforçam a subtração de direitos e o processo de desconstrução do Sistema Único de Saúde em curso no País (Morosini, Fonseca \& Lima, 2018).

Apesar deste forte retrocesso na atualidade, a APS, da forma que foi concebida nas versões de 2006 e 2011 era entendida (e sua atuação nos últimos anos caminhou neste sentido, apesar das inúmeras deficiências e desafios) para estar a mais próxima possível da vida das pessoas. Por esta inserção privilegiada, foi pensada para atuar como o contato preferencial dos usuários, a principal porta de entrada e centro de comunicação das Redes de Atenção à Saúde (RAS), considerando o usuário em sua singularidade e inserção sociocultural e buscando produzir uma atenção integral. Na APS esse princípio se traduzia em serviços de saúde que buscavam contemplar as necessidades coletivas e específicas dos usuários e de suas famílias, lidando com demandas biológicas, psíquicas, sociais e até mesmo espirituais.
A ESF vem se configurando ao longo do tempo como uma importante política de reorganização dos modelos de atenção do SUS no Brasil. Embora seja uma política induzida e financiada em grande parte pelo governo federal, a partir da descentralização progressiva do SUS, a administração cotidiana e micropolítica é de responsabilidade das gestões municipais. É dessa forma que a ESF vai assumindo características de acordo com os contextos locais e municipais, com avanços e inovações, mas também com níveis ainda incipientes de implementação e uma série de dificuldades tanto estruturais como nos processos de trabalho (Aquino, Medina, Nunes \& Sousa, 2014). O impacto da "nova" PNAB na APS brasileira só poderá realmente ser sentida a partir de estudos que se farão daqui para a frente.

\section{A inserção da Psicologia na APS}

Em termos históricos, os profissionais da Psicologia têm atuado na APS desde as primeiras experiências de matriciamento, especialmente no apoio às equipes de Saúde da Família (eSF) sobre como prestar cuidados aos portadores de sofrimento psíquico e seus familiares (Dimenstein, 1998). Segundo Jimenez (2011) o percurso da psicologia na APS dos serviços públicos de saúde brasileiros tem seu marco inicial na década de 1980, onde uma conjunção de propostas e reivindicações apontava para a necessidade de mudanças importantes na abordagem dos problemas de saúde, enfatizando a contribuição da psicologia nas equipes multiprofissionais.

Segundo Dimenstein (1998), a partir da década de 1980, principalmente, podemos ver algumas inserções dos profissionais da Psicologia na APS, principalmente nas Unidades Básicas de Saúde (UBS). Estas UBS, criadas ainda na década de 1930, passaram aos poucos a ter como objetivo a recuperação, a promoção de saúde e a prevenção de doenças e agravos, obtidos por meio do atendimento integral às pessoas. Objetivando esse atendimento integral e a realização de uma visão sócio-ecológica do processo saúde-doença que deveria ser transmitida à comunidade, a experiência da inserção da Psicologia nessas UBS revelou-se um grande desafio, considerando as dificuldades na adequação e no modelo proposto para o trabalho, o tipo de clientela atendida e a necessidade de se pensar 
uma ação diferenciada daquelas às quais estavam acostumados os profissionais da Psicologia.

Com a implantação em 1993 do Programa Saúde da Família (PSF), a Psicologia ficou excluída da equipe mínima de profissionais, atuando em alguns municípios diretamente na APS (Jimenez, 2011) ou na retaguarda do trabalho das equipes de saúde da família através de serviços substitutivos. Mas, mesmo atuando em UBS de alguns municípios brasileiros após a implantação do PSF, é apenas em 2008, com a criação dos Núcleos de Apoio à Saúde da Família (NASF), que a Psicologia terá uma presença mais significativa na Atenção Básica. Jimenez (2011) destaca que, visando à integralidade como diretriz, a proposta do NASF previu um profissional de Saúde Mental em cada núcleo como condicional ao seu funcionamento devido à grande magnitude epidemiológica dos transtornos mentais no Brasil.

Pensando no campo específico da Saúde Mental, a inserção de profissionais da Psicologia e de outros trabalhadores da saúde no NASF foi pensada como forma de avançar e aprofundar não apenas a Reforma Sanitária, mas, principalmente, a Reforma Psiquiátrica Brasileira (RPB), dada a extensa capilaridade das ESF nos territórios, sua maior proximidade com as famílias e usuários e pela longitudinalidade do cuidado. Desta forma, o NASF foi (e de certa forma ainda é) uma das grandes apostas do Ministério da Saúde para o aumento tanto quali como quantitativo das ações em Saúde Mental no SUS. O NASF inserido na APS e mais especificamente na ESF foi concebido para uma atuação multiprofissional e interdisciplinar, onde existam ações conjuntas e onde os saberes e as especialidades se entrecruzem, produzindo novos modos de relação com os usuários, o reposicionamento dos conhecimentos técnicos utilizados pelos profissionais de saúde e o desenvolvimento de novas formas de cuidado (Paulon \& Neves, 2013).

A Psicologia foi e vai, assim, se inserindo cada vez mais nos dispositivos da RPB, passando por intensos questionamentos e rupturas paradigmáticas em sua atuação. Pesquisas realizadas nos últimos anos (Cambuy \& Amatuzzi, 2012; Azevedo \& Kind, 2013) mostram que as ações dos profissionais da Psicologia na APS e mais especificamente nos NASF envolvem ao mesmo tempo a reprodução do mode- lo biomédico e clínico, mas também a utilização de experiências inovadoras desenvolvidas no campo da Saúde Coletiva

\section{Impactos no processo formativo e na prática dos profissionais da Psicologia}

As mudanças nos paradigmas das políticas de saúde a partir do estabelecimento do SUS convocaram os profissionais da Psicologia a repensarem suas práticas: a ciência e a prática psicológica no Brasil, historicamente descomprometida com a questão social brasileira, começa paulatinamente a tentar desenvolver novas linguagens, técnicas e estratégias para poder lidar com as inúmeras demandas sociais trazidas por uma inserção que objetiva promover a saúde da coletividade e uma melhor qualidade de vida para a população.

Nos momentos iniciais de inserção da Psicologia nas políticas de saúde, os psicólogos e psicólogas atuavam em grande parte enfocando os fenômenos da vida intrapsíquica dos usuários, sem compreendê-los a partir de suas multideterminações e complexidades, desconsiderando o contexto social, cultural, econômico e político no qual os pacientes estavam imersos (Dimenstein, 1998). Algumas das principais consequências deste enfoque intrapsíquico foram: o desenvolvimento de uma clínica tradicional e elitista como estratégia principal de trabalho; a dificuldade em delimitar o papel específico do psicólogo nas políticas de saúde; a desconsideração das questões sociais; a incongruência entre a tradição intervencionista e adaptativa da profissão versus as exigências do SUS por ações multi e interprofissionais, preventivas, promotoras da saúde e comunitárias, entre outras.

Pesquisas realizadas mais recentemente (Cambuy \& Amatuzzi, 2012; Azevedo \& Kind, 2013; Silva et. al., 2012) mostram que as ações dos profissionais da Psicologia na APS e mais especificamente nos NASF estão bastante diversificadas em relação às temáticas, às formas e aos públicos atendidos, desenvolvendo práticas e olhares inovadores, desenvolvidas principalmente por profissionais atuando a partir da perspectiva e no campo da Saúde Coletiva, trazendo novos "ares" para a atuação profissional da Psicologia. Entre elas podemos citar: o apoio matricial, a clínica ampliada, o projeto tera- 
pêutico singular (PTS), atividades de articulação da Rede de Atenção à Saúde, o uso de teorias e técnicas de modo inovador, diálogos e parcerias com as universidades, trabalho com populações específicas, ações com as famílias, trabalhos com grupos, implementação de programas e políticas públicas, entre várias outras possibilidades.

O psicólogo tem se tornado ao longo do tempo um trabalhador essencial na APS (Dimenstein, 2011), na medida em que tem tentado promover a participação da comunidade no seu autocuidado e ainda se transformar no ponto de intersecção entre a comunidade e a equipe de Saúde da Família. Todavia, a massificação da entrada de profissionais da Psicologia na APS aproximou a profissão de uma realidade ainda distante do que é discutido e vivenciado em grande parte dos cursos de graduação em Psicologia no Brasil (Guareschi, Scileski, Reis, Dhein \& Azambuja, 2010). Trabalhando em sua maior parte com uma população de baixa renda $e$ lidando com uma série de vulnerabilidades (sociais, políticas, econômicas, emocionais, familiares, etc.), os profissionais da Psicologia se sentem confusos neste espaço. $O$ encontro com comunidades, em geral de baixa renda, contribue para o questionamento das ferramentas de trabalho profissional e para o aparato teórico-técnico que deve ser utilizado em intervenções interdisciplinares por meio de equipes multiprofissionais. (Dimenstein, 2011).

Inseridos nos NASF ou em unidades de saúde (UBS, por exemplo) e atuando junto a uma população de baixa renda, os profissionais da Psicologia têm de lidar muitas vezes com uma linguagem, cultura e sociabilidades que the são desconhecidas e/ou estranhas. Dessa forma, o profissional da Psicologia atuante na APS se encontra em uma encruzilhada (Dimenstein, 2011): atua muitas vezes a partir do modelo biomédico (que desconsidera o humano, sua subjetividade e história e só foca na patologia ou, no caso da Psicologia, na psicopatologia), na tentativa não reflexiva do enquadramento dos usuários em uma identidade e uma "saúde mental" hegemônica e reprodutora das desigualdades; em outros momentos, atua em uma perspectiva de emancipação da cidadania, configurando ações que implicam possibilidades de luta e de protagonismo para os indivíduos. Essa aparente contradição pode indicar um momento de transição dos processos de forma- ção, em que existem elementos de uma formação descontextualizada e outro modelo que se forma e que lida com os princípios do SUS e da Saúde Coletiva.

Segundo Dimenstein (2011), os profissionais da Psicologia se sentem estranhos na APS: estão com medo, frustrados e ressentidos por não conseguirem atuar em um espaço no qual as teorias e técnicas da Psicologia não dão conta das demandas da população e inexiste a sensação de estabilidade e segurança. A população e os outros trabalhadores da saúde não sabem o que esperar da Psicologia além de uma atuação clínica e individual. Para muitos destes psicólogos, a segurança se daria em atuar a partir do modelo de profissional liberal, na perspectiva de uma clínica tradicional tão amplamente ensinada nos cursos de graduação em Psicologia: em cada unidade de saúde haveria um consultório montado segundo uma série de especificações técnicas (com ar condicionado, cadeiras e mesas confortáveis, isolamento acústico da melhor qualidade, entre outros aspectos) e uma lista de pessoas previamente agendadas e com seus horários marcados.

Além disso, muitos profissionais da Psicologia se sentem desconfortáveis não apenas com as (im)possibilidades da atuação, mas também com a realidade social com a qual lidam. E essa realidade é por vezes tão brutal que estes profissionais se percebem como meros espectadores frente ao imenso sofrimento de pessoas, famílias, da comunidade como um todo. As situações mais diversas ocasionadas pelas mais diferentes formas de exclusão (pobreza, desemprego, criminalidade, violência, tráfico e uso abusivo de drogas, entre outras tantas) dão a este profissional uma extrema sensação de impotência frente ao tamanho da problemática vivenciada, chegando mesmo a questionar sua função nesta política e se está de fato dando alguma contribuição concreta a essa população (Dimenstein, 2011).

Muitas reflexões teóricas (Paulon \& Neves, 2013; Azevedo \& Kind, 2013) têm sido realizadas a respeito da inserção da Psicologia na APS. Todavia, encontramos poucos relatos de uma Atenção Psicossocial inserida não apenas na APS, mas também nas possibilidades de articulação desta com outros pontos e serviços tanto das RAPS como das Redes de Atenção à Saúde (RAS). Desta forma, este 
é o objetivo deste artigo: descrever e analisar uma série de experiências vivenciadas em uma proposta de estágio supervisionado em Psicologia realizado na APS e na complexidade derivada da necessidade de se ampliar o olhar sobre o campo da saúde mental e de uma atuação em rede. Esperamos contribuir dessa forma com uma lacuna do conhecimento a respeito das possibilidades de atuação dos profissionais da Psicologia na Atenção Primária e na sua articulação em rede e de que maneira essa articulação pode ser pensada e estimulada no processo de formação dos profissionais da Psicologia.

\section{Método}

\section{Participantes}

Participaram desta experiência de Estágio Supervisionado Básico turmas de no máximo 8 estudantes do curso de graduação em Psicologia da Universidade Federal do Recôncavo da Bahia (UFRB) matriculados no sétimo ou oitavo semestres do curso. Estes estudantes eram divididos em duplas ou trios no decorrer do estágio.

\section{Ambiente e contextualização}

Esta experiência aqui descrita tem início no ano de 2011 no âmbito do município de Santo Antônio de Jesus (SAJ). A ideia original era realizar uma inserção de discentes na Estratégia de Saúde da Família (ESF) junto a equipes de Saúde da Família (eSF's) e equipes do NASF no percurso de um semestre, o tempo do Estágio Supervisionado Básico. Naquele momento, o principal objetivo da proposta era ampliar o conhecimento teórico-prático sobre a atuação e as possibilidades de ação da psicologia no SUS e na APS em especial. A proposta pretendia que os discentes desenvolvessem ações junto às equipes e aos usuários a partir da análise das demandas sócio-epidemiológicas da realidade da população e dos territórios nos quais as USF's estavam inseridas. No decorrer dos semestres o objetivo da proposta original foi se aperfeiçoando e passou a prever o desenvolvimento de ações que facilitassem e tencionassem a comunicação entre os usuários e os trabalhadores da saúde a partir da APS como ponto articulador e organizador da Rede de Atenção
Psicossocial (RAPS). Essa mudança gradual do objetivo do estágio implicou no aumento da abrangência da proposta inicial e de suas possibilidades de articulação com os serviços de saúde e com as RAS. Esta experiência de estágio durou até $\circ$ ano de 2017.

A proposta do estágio teve desde o seu início a intenção de proporcionar ao discente uma sólida formação baseada na discussão com a literatura e a legislação a respeito da temática e uma imersão real e efetiva na APS de Santo Antônio de Jesus, considerando também as possíveis interfaces com os outros níveis de densidade tecnológica do SUS e com outras políticas setoriais (tais como a Assistência Social e a Educação).

Seu principal foco se baseou na atuação do discente a partir de uma Atenção Psicossocial aplicada no contexto da APS e em uma intervenção com base nos princípios do campo da Saúde Coletiva, dos Direitos Humanos e da Psicologia Social-Comunitária, considerando a lógica de uma atuação interprofissional que pode e deve se pautar nos princípios do matriciamento em Saúde Mental (Campos, 1999; 2000; 2003 ; 2003). Esta perspectiva de atuação proposta entendia, dessa maneira, que a atuação do profissional da Psicologia na APS deveria se basear em uma leitura crítica, dialética e comprometida socialmente com a realidade da população.

\section{Procedimentos de produção de dados}

O estágio começava a cada semestre a partir de uma articulação com a Secretaria Municipal de Saúde (SMS) de Santo Antônio de Jesus (SAJ) no sentido de definirmos em quais Unidades de Saúde da Família (USF) os discentes desenvolveriam suas atividades. Inicialmente, esta inserção se dava a partir de uma vivência etnográfica/observacional, desenvolvida normalmente durante 3 ou 4 semanas, onde os discentes iam conhecendo a USF, sua estrutura física, seus trabalhadores, usuários e também o território no qual estava inserida. Junto com esta inserção etnográfica, o discente ia compondo sistematicamente um diário de campo onde descrevia objetiva/subjetivamente suas impressões sobre todos os aspectos possíveis que fariam interface com o desenvolvimento do estágio: as ações realizadas, dificuldades e desafios nas atividades individuais e 
coletivas, possibilidades de intervenção, análise da realidade das equipes (eSF e NASF), relações interpessoais, as condições de saúde da população, entre outros aspectos.

O objetivo desta etnografia inicial era conseguir descrever e realizar um diagnóstico da USF que subsidiasse a elaboração de um projeto de intervenção que cada dupla/trio de discentes deveria realizar durante o estágio. É importante considerar que não existia a priori a determinação de quais atividades seriam desenvolvidas pelos discentes. A proposta do estágio levava em consideração a liberdade e a capacidade de análise do discente em compreender e propor ações condizentes com a realidade de cada USF. As propostas das duplas eram acolhidas e discutidas coletivamente nas reuniões de supervisão, que aconteciam semanalmente. A partir de suas observações na etnografia e da análise da realidade de cada USF, construíamos em conjunto um projeto de intervenção que serviria de referência para a dupla durante o decorrer do estágio. Esse projeto muitas vezes (quase sempre) acabava sendo modificado a partir da dinâmica da atuação no serviço.

\section{Procedimentos de análise de dados}

A partir da análise da realidade e da construção do projeto de intervenção, os discentes passavam a atuar como profissionais da Psicologia em formação, vivenciando as alegrias e dificuldades encontradas por um profissional que adentra pela primeira vez no âmbito do SUS com todas suas idiossincrasias e problemáticas. A partir da análise dos dados acumulados nos diários de campo e nas supervisões de estágio, as informações acumuladas foram organizadas e sistematizadas nos eixos centrais de descrição que compuseram os relatórios confeccionados no final de cada estágio.

É importante considerar que, apesar deste artigo considerar e descrever a observação e a troca de experiências entre estagiários, profissionais de saúde e usuários, por ter sido uma experiência de estágio curricular, a mesma não precisou passar por um Comitê de Ética em pesquisa com seres humanos.

\section{Resultados e Discussão}

Este estágio básico em específico era, para muitos discentes, a primeira experiência na prática profissional da Psicologia e a primeira inserção no SUS. Como primeira prática profissional, muitos discentes chegavam ao estágio com muita ansiedade sobre o que de fato iriam realizar, qual o papel e a postura do profissional da Psicologia em campo. Muitos relatavam que, se não tivessem participado de algum projeto de pesquisa ou de extensão antes da entrada no estágio básico, esta seria a primeira vez de fato que atuariam na prática e com "pessoas". Por isto a ansiedade era algo bastante presente logo nas primeiras semanas do estágio.

É claro que o SUS e toda sua política multifacetada e complexa exerce um enorme fascínio no estudante de Psicologia, considerando o número de profissionais da Psicologia aí inseridos. Principalmente com a implantação dos NASF a partir de 2008, o SUS é hoje a política pública onde existe o maior número de psicólogas e psicólogos atuando (Ferreira Neto, 2011 ) e onde existe também a possibilidade real de inserção dos futuros egressos da graduação em Psicologia da UFRB.

A prática profissional de estagiários na APS trouxe à tona novos e velhos problemas no âmbito do SUS: a influência da política partidária na inserção dos profissionais de saúde e nos rumos da saúde; uma série de dificuldades estruturais (unidades de saúde sem estrutura adequada, dificuldade de espaço para atendimento, falta de materiais, etc.); precarização do vínculo trabalhista; descompromisso dos trabalhadores da saúde; falta de educação permanente em saúde, entre outros aspectos (Paim \& Almeida-Filho, 2014). Estas questões foram observadas pelos discentes e, discurso recorrente destes, se apontou o imenso abismo ainda existente entre a teoria/legislação e a prática cotidiana dos trabalhadores da saúde no SUS.

Além disso, no caso específico da Psicologia, a inserção na APS convocou os discentes a lidarem com situações bastante desafiadoras com as quais a Psicologia ainda não tinha respostas: dificuldades em compreender os determinantes sociais envolvidos nos processos de saúde-doença; a necessidade de 
um trabalho multiprofissional e interdisciplinar efetivo; a articulação com a Rede de Atenção à Saúde; a utilização de "tecnologias" do cuidado vindas de outras áreas e categorias profissionais; dificuldades com a "linguagem" da saúde; atuação com outras categorias que atuam a partir de uma lógica ambulatorial clássica, entre outras (Dimenstein, Lima \& Macedo, 2013). Esses aspectos foram continuamente observados nas USF e foram pensadas estratégias de enfrentá-las e superá-las.

No início da proposta de estágio foi estabelecida uma parceria com as profissionais da Psicologia atuantes no NASF para que o trabalho fosse realizado através da existência de uma preceptoria em campo. Todavia, a partir de algumas ações em conjunto durante dois semestres, realizei uma avaliação e a parceria não foi continuada. A lógica da descontinuidade da parceria partiu da constatação de que a atuação das profissionais da Psicologia atuantes no NASF estava bem distante da forma como foi pensada e concebida por pesquisadores e teóricos do campo da Saúde Coletiva, além daquilo que é explicitamente preconizado pelo Ministério da Saúde brasileiro (Leite, Andrade \& Bosi, 2013; Paulon \& Neves, 2013). De fato, o trabalho da Psicologia no NASF não funcionava, naquele momento em específico, como um dispositivo que atuasse de forma interdisciplinar e como um elemento ao mesmo tempo aglutinador e atuante a partir do paradigma do Apoio Matricial, se pautando na maior parte das vezes em uma perspectiva biomédica, clínica, individual e desarticulada da realidade social e epidemiológica do território e da população.

É importante destacar que baseamos nossas atividades em campo principalmente no referencial teórico-metodológico do apoio matricial. Esse referencial, formulado por Campos (1999; 2003; 2007), propõe uma série de arranjos e dispositivos para estimular a democratização da gestão, a interdisciplinaridade e a ampliação da clínica. A noção de apoio indica uma atuação multi e interprofissional onde cada profissional deverá buscar apoio em outras especialidades para desenvolver suas ações. Aqui reside a base do apoio matricial: profissionais de áreas especializadas, que não estão envolvidos no seu cotidiano com as demandas da equipe de referência, oferecem suporte técnico especializado às mesmas: o núcleo especializado dá suporte ao campo interdisciplinar das equipes de referência. A noção de um Apoio Matricial comporta dois tipos de retaguarda especializada: clínico-assistencial e técnico-pedagógica. A dimensão clínico-assistencial é aquela que vai produzir ação clínica direta com os usuários, enquanto a dimensão técnico-pedagógica vai produzir ações de apoio educativo com e para a equipe de saúde.

Pensamos nossas atividades de estágio a partir das duas dimensões contidas no referencial do apoio matricial: clínico-assistencial e técnico-pedagógica. Não tendo um direcionamento a priori, as ações desenvolvidas consideraram a realidade epidemiológica, cultural e socioeconômica de cada população adstrita, na tentativa de realizar ações que incidissem sobre as demandas mais prementes da população e do território.

No que diz respeito à dimensão clínico-assistencial, as principais ações desenvolvidas foram: atividades em grupo, atividades de sala de espera, atendimentos individuais, visitas domiciliares e interconsultas.

As atividades em grupo foram as mais desenvolvidas pelas duplas/trios em campo. Muito se tem falado sobre a amplitude das ações da Psicologia no SUS através da realização de grupos como forma de atingir e aumentar o impacto na coletividade dos usuários (Paulon \& Neves, 2013). Algumas orientações oficiais (Ministério da Saúde, 2014) enfatizam as práticas grupais como importante recurso no cuidado aos usuários da APS, entendendo que estas práticas não podem ser pensadas como forma de dar conta de uma demanda apenas quantitati$\mathrm{va}$, mas enquanto ações que propiciam socialização, integração, apoio psíquico, trocas de experiências e de saberes e construção de projetos coletivos. A principal função de muitos desses grupos deverá se situar na educação em saúde, sendo o empoderamento, o desenvolvimento da autonomia, a participação e a co-responsabilização dos usuários alguns de seus objetivos.

Foi a partir dessas premissas que as duplas/trios desenvolveram suas ações nos grupos. Entretanto, entre as várias possibilidades de configuração sob o rótulo de "grupo" (conceito polissêmico), tivemos duas principais configurações: grupos de educação em saúde e salas de espera em grupo. Estas ativi- 
dades foram direcionadas a vários públicos: crianças, adolescentes, mulheres, idosos, pais, hipertensos, diabéticos, gestantes e cuidadores, principalmente de idosos.

Chamo aqui de educação em saúde o conjunto de ações desenvolvidas por profissionais da saúde que têm por objetivo a reconfiguração de conhecimentos, atitudes e comportamentos, na busca da melhoria da qualidade de vida e de saúde para o usuário. Os estagiários desenvolviam em grupo uma abordagem que veiculava novos conhecimentos sobre uma determinada temática, sempre buscando a adequação da linguagem para o público a quem se destinava. Além disso, os estagiários eram estimulados a utilizar neste espaço o formato e a postura do trabalho das oficinas educativas, onde a dupla de discentes se colocava na postura de facilitadora das atividades, sempre empoderando os usuários na proposição de temas, atividades e na própria condução da atividade.

O público, a temática e a periodicidade de cada grupo foram discutidos entre os estagiários e as equipes de Saúde da Família. Definida a composição e dinâmica de determinado grupo, geralmente precisava-se da colaboração indispensável dos Agentes Comunitários de Saúde (ACS) e das enfermeiras das USF: os principais divulgadores e articuladores das atividades desenvolvidas nas unidades de saúde.

Muitas vezes o grupo era definido e composto e começava a funcionar da forma prevista durante algum tempo. Todavia, por uma série de motivos, alguns deles acabavam não tendo mais participantes e deixavam de existir. Alguns desses motivos observados na prática foram: falta de apoio e divulgação da atividade (principalmente pelos ACS), falta de lanche (às vezes a única motivação para frequentar - grupo) e o não interesse dos usuários, por já terem participado de uma série de atividades em grupo na USF. Um empecilho que tivemos foi o tempo de duração dos grupos conduzidos pelos estagiários: normalmente entre 6 a 8 encontros. Isso implicava muitas vezes no desinteresse de alguns usuários em participar dos grupos, pelo curto espaço de tempo de sua existência.
É importante considerar que esta atividade em específico trouxe aos discentes as maiores alegrias e as maiores frustrações em seus estágios. Alegria porque conseguiram desenvolver grupos nos quais perceberam uma série de mudanças nos usuários (recebendo inclusive vários retornos significativos destes); frustração quando não conseguiam realizar o grupo, quando apenas poucos usuários frequentavam e quando os estagiários entendiam que o objetivo do grupo não tinha sido alcançado. De qualquer forma, realizar grupos por um tempo considerável é sempre um desafio no âmbito do SUS, e esses discentes conseguiram perceber na prática esse desafio.

As práticas em grupo nas quais os discentes perceberam uma maior participação e envolvimento dos usuários foram aquelas nas quais os estagiários conseguiram de fato criar um canal de comunicação efetivo com estes, em que existia uma escuta e um interesse real naquilo que o usuário trazia (de relato e/ou conhecimento); em que o usuário se colocava em um lugar ativo e propositivo em relação às temáticas discutidas, formas de organização e condução do grupo.

Outra ação também bastante presente nas práticas de estágio foram as salas de espera. Sob o nome de sala de espera eram desenvolvidas atividades de educação em saúde nas salas de espera das USF. Normalmente os discentes traziam para a discussão assuntos que estavam em pauta naquela unidade de saúde em especial durante determinado período (tal como diabetes, hipertensão, alimentação saudável, entre outros) ou, a partir de suas análises em dupla (tal como saúde mental, depressão, relações interpessoais, desenvolvimento infantil etc.).

Nas salas de espera o mais comum era que os estagiários levassem uma programação do que e como seriam trabalhadas as temáticas, muitas vezes distribuindo materiais informativos cedidos pela SMS ou organizados por eles próprios. Em outros momentos, os discentes abriam o debate sobre uma temática como forma de ouvir o que os usuários tinham a dizer sobre, deixando o tema para livre discussão. Via de regra, as salas de espera eram momentos que duravam entre 20 a 30 minutos e o grande desafio era conseguir a atenção dos usuários e envolvê-los no debate. Muitas vezes os estudantes conseguiram 
esse objetivo e tiveram discussões bem interessantes com os usuários; outras vezes a atenção e o debate não aconteciam, o que também trazia momentos de frustração e a reflexão a respeito de elaborar formas mais envolventes de participação.

Os atendimentos individuais também foram realizados pelos estagiários. Na realidade, sob o rótulo de "atendimento individual", foram desenvolvidas algumas formas de interação com os usuários de forma individual, que envolveram algum tipo de manejo clínico com os mesmos. Uma dessas formas dizia respeito a um acolhimento inicial ou um primeiro atendimento desse usuário que era encaminhado pela eSF ou que surgiu de forma espontânea na USF. Nesse acolhimento podia haver a identificação da problemática e o encaminhamento para a RAS/ RAPS. Outra modalidade de atendimento individual desenvolvido foi a realização de um plantão psicológico em uma USF. Por uma demanda da unidade de saúde, as estagiárias destinavam um tempo de seus estágios para a realização de uma escuta espontânea para os usuários, onde houve uma adesão e retorno muito interessante dos usuários.

Outra modalidade também desenvolvida pelos estagiários foi a realização de interconsultas. Essa ação foi desenvolvida em uma das USF na qual existia uma médica cubana, atuando a partir do programa Mais Médicos do Ministério da Saúde. Destaco aqui que, onde existiam médicas cubanas nas USF, o trabalho era bem mais facilitado e as médicas se dispunham a realizar uma série de atividades com os estagiários, tais como salas de espera, interconsulta, trabalhos em grupo, etc. Atividades essas que não tinham aderência dos médicos brasileiros.

Os estagiários também realizaram visitas domiciliares. Essas visitas aconteciam geralmente com usuários acamados ou com dificuldades de se deslocar para as USF. As visitas aconteciam mediadas pela articulação e presença dos ACS, algumas vezes com o acompanhamento de profissionais do NASF ou da eSF. Um desdobramento dessas visitas foi também a discussão dos casos entre os profissionais e os estagiários e o estabelecimento de algumas linhas de intervenção para os usuários. As visitas domiciliares trouxeram ganhos bastante significativos para os discentes, a partir do próprio relato dos mesmos.
Além da dimensão clínico-assistencial, havia o incentivo em cada novo semestre para que os estagiários realizassem ações técnico-pedagógicas direcionadas às equipes de saúde. A principal atividade desenvolvida neste aspecto foram atividades em grupo direcionadas aos ACS. Houveram aqui várias tentativas de realização de ações com outros profissionais de saúde que não se concretizaram, mas destaco que a principal resistência encontrada neste sentido foi que muitos profissionais acreditavam que a pouca experiência dos estagiários de Psicologia os incapacitava de desenvolver qualquer atividade com profissionais de saúde já formados e com experiência.

Durante o diagnóstico inicial e na busca pelas demandas das unidades, alguns coletivos de ACS em algumas USF indicaram que precisavam saber mais sobre as questões que envolviam a Saúde Mental, mas, principalmente, que precisavam ter momentos em que pudessem falar e expressar as inúmeras dificuldades vivenciadas em seu cotidiano de trabaIho. Quando estas atividades aconteciam, havia um crescimento pessoal e profissional bem interessante entre os estagiários e os ACS através da troca de experiências e da possibilidade de expressar e ressignificar suas demandas diárias tão cansativas no plano físico e também relacional, já que estes profissionais se queixavam continuamente da desvalorização pela qual sofriam por parte dos outros profissionais de saúde.

Outro campo de ação vivenciado pelos estudantes foi a demanda de articulação com a RAPS e RAS do município. Muitos dos usuários atendidos pelos estagiários tinham demandas que nitidamente extrapolavam os serviços ofertados nas USF's e tinham demandas em outros pontos das redes.

No campo específico da saúde mental, a cultura institucional da APS do município era de encaminhar para as psicólogas do NASF qualquer tipo de situação que fosse avaliada como tendo relação com a saúde mental: de conflito familiar a transtorno mental grave e persistente. Como o foco dos atendimentos da Psicologia no NASF não era o atendimento psicoterápico individual continuado, estas psicólogas normalmente faziam o acolhimento desses usuários e os encaminhavam para o ambulatório de saúde mental e para o CAPS II do município, considerados 
os pontos centrais da RAPS. Todavia, tanto o referido ambulatório como o CAPS em questão não recebiam demandas de conflitos familiares, casos de dificuldades de aprendizagem de crianças de adolescentes e até dores de cabeça (situações bastante frequentes). A RAPS municipal não tinha à época, em nenhum nível de densidade tecnológica, qualquer serviço que atendesse esse perfil de usuário. Este deveria ser atendido em tese pelas psicólogas do NASF, o que não acontecia de forma sistemática. Dessa forma, se criava uma lacuna nas possibilidades de atendimento destes usuários na APS.

Uma das frentes de atuação dos estagiários atuou exatamente nesta lacuna. Uma das ações realizadas foi acompanhar alguns usuários encaminhados de algumas USF's para o CAPS. Alguns estagiários acompanhavam estes usuários nas primeiras consultas com a equipe do CAPS e nos desdobramentos que surgiam a partir daí. Uma das principais problemáticas encontradas foi que o CAPS em questão não dava continuidade aos atendimentos e este usuário "retornava" para sua USF sem perspectiva de cuidado. Foram realizadas aqui uma série de intervenções com esses usuários que iam desde uma escuta sistemática realizada na própria unidade de saúde, atividades em grupo com usuários com o mesmo perfil (gestantes, idosos, adolescentes, etc.) até articulações na RAPS/RAS sobre outras demandas que extrapolavam o campo da "saúde mental": marcação de consultas, exames e até mesmo cirurgias.

Esse realmente foi um dos aspectos mais desafiadores enfrentados pelos estagiários, já que claramente não existia no município uma cultura e uma gestão pensada em rede. $O$ princípio fundamental da APS, mesmo com a presença da Psicologia, era de identificar os usuários com demandas no campo da Saúde Mental e referenciar para o CAPS e para o ambulatório do município. A partir daí a responsabilidade com o cuidado era apenas da atenção especializada. Como não existia um cuidado sistemático em saúde mental nas USF's e era evidente um sentimento de não responsabilidade das equipes de saúde em relação à temática, o trabalho no estágio também se deu muito fortemente em matriciar informações e práticas para os profissionais de saúde no campo da saúde mental a partir de conversas informais, vivências formativas e repasses de literatura especializada.

\section{Considerações Finais}

Entendo que a ação da Psicologia na APS, mais do que desenvolver novas tecnologias no cuidado à saúde, deve se pautar na capacidade de ler o contexto das necessidades sociais e de saúde da população para pensar o tipo de cuidado que esta necessita. Mais do que atuar a partir de "novas" tecnologias do cuidado (que podem inclusive enquadrar e cercear a liberdade criativa), o profissional da Psicologia necessita desenvolver um olhar diferenciado sobre a saúde. Isso o campo da Saúde Coletiva pode nos mostrar e referenciar muito bem.

Como a própria história da Psicologia demonstra (Ferreira Neto, 2012), não temos ainda um lastro de experiência e de teoria suficientes no qual os psicólogos em formação possam se referenciar para atuar neste âmbito. Esse lastro está sendo construído no momento, não só pelos profissionais que estão no campo como também a partir dos pesquisadores e entidades da Psicologia que tentam investigar esse campo de atuação profissional. Nos últimos anos, tem havido uma reflexão maior sobre a necessidade de mudança a respeito do papel dos profissionais da Psicologia no SUS como um todo e na APS em específico.

As novas diretrizes curriculares para os cursos de graduação em Psicologia (Brasil, 2004; 2011 ) estão alinhadas com as premissas do SUS e contemplam um novo tipo de profissional da Psicologia. Elas corroboram a formação de um profissional que não se fundamenta apenas no estabelecimento de padrões de comportamento descritivos e que estabelecem o que é normal ou patológico. Propõem também que o profissional não se paute apenas em disciplinar as condutas a partir do que estabelece como "certo" ou "errado", normal ou patológico, mas um psicólogo que respeite a alteridade, a diferença, que compreenda as condições de produção de subjetividades em seus contextos sociais e históricos (Guareschi, Scileski, Reis, Dhein \& Azambuja, 2010).

Nesse sentido, a formação do curso de graduação em Psicologia da UFRB proporciona, não só a partir desta experiência de estágio, mas a partir também de tantas outras discussões e vivências proporcionadas aos discentes durante o curso, uma visão crítica 
e reflexiva sobre o SUS e sobre as possibilidades de uma inserção qualificada destes profissionais neste âmbito.

Ainda hoje, grande parte dos novos profissionais da Psicologia está sendo formada nas graduações brasileiras para trabalhar a partir de um modelo clínico hegemônico e tradicional, com pouco ou nenhum conhecimento sobre o SUS (Guareschi, Scileski, Reis, Dhein \& Azambuja, 2010). Assim, esses profissionais concluem sua graduação e passam a trabalhar no SUS sem um olhar sensível para os diversos determinantes no processo saúde-doença, sem comprometimento com as transformações sociais e sem conhecimento para atuar nesta política pública.

Para a Psicologia se aproximar do SUS e da APS, faz-se necessário que barreiras sejam ultrapassadas em termos de uma identidade profissional arraigada em sua história (Jimenez, 2011). É a partir dessa transformação que o profissional poderá estar integrado com as equipes de saúde, tendo um posicionamento e um comprometimento ético-político que cuide do indivíduo de forma integral e que vá além das suas próprias diferenças de classe social e cultura com os usuários atendidos.

A experiência aqui descrita teve o claro limite de se circunscrever a uma atuação durante um semestre de um curso de graduação em Psicologia. Nesse sentido, seu escopo de intervenção e análise foi reduzido e focado. Todavia, mesmo que durante um curto espaço de tempo de intervenção, os estagiários puderam evidenciar o quanto os serviços e as equipes de saúde estavam despreparados e descomprometidos com o campo da saúde mental na APS. Além disso, perceberam a necessidade de uma articulação entre a APS e a RAPS/RAS, para se pensar realmente em um cuidado integral e integrado em rede.

Esta experiência formativa aqui apresentada intentou dar uma contribuição, ainda que singela e efêmera nas suas características, para que os egressos deste curso de Psicologia pudessem ter esta postura diferenciada e comprometida, podendo também ajudar $\circ$ SUS a se aprofundar enquanto uma política pública fundamental para o povo brasileiro, ainda que constantemente atacada na atualidade por concepções e fundamentos que $\circ$ transformam em algoz do Estado Brasileiro, ao invés de ser entendido como um direito fundamental previsto em nossa Constituição Federal e que precisa ser constantemente defendido.

\section{Conflitos de interesses}

Nenhum conflito financeiro, legal ou político envolvendo terceiros (governo, empresas e fundações privadas, etc.) foi declarado para nenhum aspecto do trabalho submetido (incluindo mas não limitandose a subvenções e financiamentos, conselho consultivo, desenho de estudo, preparação de manuscrito, análise estatística, etc.).

\section{Referências}

Aquino, R., Medina, M. G., Nunes, C. A., \& Sousa, M. F. (2014). Estratégia Saúde da Família e reordenamento do Sistema de Serviços de Saúde. In: J. S. Paim \& N. Almeida-Filho (Orgs.), Saúde Coletiva: teoria e prática (pp. 353-371). Rio de Janeiro: MedBook.

Azevedo, N. S., \& Kind, L. (2013). Psicologia nos núcleos de apoio à saúde da família em Belo Horizonte. Psicologia: Ciência e Profissão, 33(3), 520-535. Recueprado de http://www.scielo.br/pdf/pcp/ v33n3/v33n3a02.pdf . doi: 10.1590/S141498932013000300002

Resolução $N^{\circ} 8$, de 7 de maio de 2004. Institui as Diretrizes Curriculares Nacionais para os cursos de graduação em Psicologia. Recuperado de http://portal.mec.gov. $\mathrm{br} / \mathrm{cne} /$ arquivos/pdf/rces08_04.pdf

Resolução $N^{\circ}$ 5, de 15 de março de 2011 . Institui as Diretrizes Curriculares Nacionais para os cursos de graduação em Psicologia, estabelecendo normas para o projeto pedagógico complementar para a Formação de Professores de Psicologia. Recuperado de http://portal.mec.gov.br/index.php?option=com docman\&view $=$ download\&alias $=7692-$ rces005-11 pdf\&ltemid $=30192$

Cambuy, K., \& Amatuzzi, M. M. (2012). Experiências comunitárias: repensando a clínica psicológica no SUS. Psicologia \& Sociedade, 24(3), 674-683. Recuperado de http://www.scielo.br/pdf/psoc/v24n3/20.pdf. doi: $10.1590 /$ S0102-71822012000300020

Campos, G. W. S. (1999). Equipes de referência e apoio especializado matricial: um ensaio sobre a reorganização do trabalho em saúde. Ciência \& Saúde Coletiva, 4(2), 393-403. Recuperado de http://www. scielo.br/pdf/csc/v4n2/7121.pdf. doi: 10.1590/ s1413-81231999000200013 
Campos, G. W. S. (2000). Saúde pública e saúde coletiva: campo e núcleo de saberes e práticas. Ciência \& Saúde Coletiva, 5(2), 219-230. Recuperado de http://www.scielo.br/pdf/csc/v5n2/7093.pdf. doi: $10.1590 /$ S1 $113-81232000000200002$

Campos, G. W. S. (2003). Saúde Paideia. São Paulo: Hucitec.

Dimenstein, M. D. B. (1998). O psicólogo em Unidades Básicas de Saúde: desafios para a formação e atuação profissionais. Estudos de Psicologia, 3(1), 53-81. Recuperado de http://www.scielo.br/pdf/ epsic/v3n1/a04v03n1.pdf. doi: 10.1590/S1413$\underline{294 \times 1998000100004}$

Dimenstein, M. (201 1). Contribuições da Psicologia Social para a saúde como direito e construção da cidadania. In: B. Medrado, \& W. C. M. Galindo (Orgs.), Psicologia Social e seus movimentos: 30 anos de ABRAPSO (pp. 161-182). Recife: ABRAPSO/Ed. Universitária da UFPE.

Dimenstein, M., Lima, A. I., \& Macedo, J. P. (2013). Integralidade em saúde mental: coordenação e continuidade de cuidados na atenção primária. In: S. Paulon, \& R. Neves (Orgs.), Saúde mental na atenção básica: a territorialização do cuidado. Porto Alegre: Sulina.

Ferreira Neto, J. L. (2011). Psicologia, políticas públicas e o SUS. São Paulo: Escuta; Belo Horizonte: Fapemig.

Guareschi, N. M. F, Scileski, A., Reis, C., Dhein, G., \& Azambuja, M. A. (2010). Psicologia, formação, políticas e produção em saúde. Porto Alegre: EDPUCRS.

Jimenez, L. (2011). Psicologia na Atenção Básica à Saúde: demanda, território e integralidade. Psicologia \& Sociedade, 23(n. espec.), 129-139. Recuperado de http://www.scielo.br/pdf/psoc/ v23nspe/al 6v23nspe.pdf. doi: 10.1590/S0102$\underline{71822011000400016}$

Leite, D. C., Andrade, A. B., Bosi, M. L. M. (2013). A inserção da psicologia nos núcleos de apoio à saúde da família. Physis Revista de Saúde Coletiva, 23(4), 1 167-1 187. Recuperado de http://www.scielo.br/ pdf/physis/v23n4/08.pdf. doi: 10.1590/S010373312013000400008

Mello, G. A., Fontanella, B. J. B., \& Demarzo, M. M. P. (2009). Atenção Básica e Atenção Primária à Saúde: origens e diferenças conceituais. Revista de APS, 12 (2), 204213. Recuperado de https://aps.ufjf.emnuvens.com. $\mathrm{br} / \mathrm{aps} /$ article/view/307/203
Portaria $n^{\circ}$ 648/GM de 28 de março de 2006. Aprova a Política Nacional de Atenção Básica, estabelecendo a revisão de diretrizes e normas para a organização da Atenção Básica para o Programa Saúde da Família (PSF) e o Programa Agentes Comunitários de Saúde (PACS). Recuperado de http://bvsms.saude. gov.br/bvs/publicacoes/politica_nacional_atencao_ basica_2006.pdf

Portaria No 2488, de 21 de outubro de 2011 . Aprova a Política Nacional de Atenção Básica, estabelecendo a revisão de diretrizes e normas para a organização da Atenção Básica, para a Estratégia Saúde da Família (ESF) e o Programa de Agentes Comunitários de Saúde (PACS). Recuperado de http://bvsms.saude.gov. $\mathrm{br} / \mathrm{bvs} /$ saudelegis/gm/2011/prt2488_21_10_2011. $\mathrm{html}$

Ministério da Saúde (2014). Núcleo de Apoio a Saúde da Família / Ministério da Saúde, Secretaria de Atenção à Saúde, Departamento de Atenção Básica. Brasília: Autor. Recuperado de http://bvsms.saude.gov.br/bvs/ publicacoes/nucleo_apoio_saude_familia_cab39.pdf

Portaria N. 2436, de 21 de setembro de 2017. Aprova a Política Nacional de Atenção Básica, estabelecendo a revisão de diretrizes para a organização da Atenção Básica, no âmbito do Sistema Único de Saúde (SUS). Recuperado de http://bvsms.saude.gov.br/bvs/ saudelegis/gm/2017/prt2436_22_09_2017.html

Mendes, E. V. (2005). Entrevista: O SUS e a Atenção Primária à Saúde. Revista de APS, 8(2), 13-25. Recuperado de http://www.ufjf.br/nates/files/2009/12/entrevista 1. pdf

Morosini, M. V. G. C., Fonseca, A. F., Lima, L. D. (2018). Política Nacional de Atenção Básica 2017: retrocessos e riscos para o Sistema Único de Saúde. Saúde Debate, 42(1 16), 11 -24. doi: 10.1590/01031104201811601

Paim, J. S., Almeida-Filho, N. (2014). Saúde Coletiva: teoria e prática. Rio de Janeiro: MedBook.

Paulon, S. M., \& Neves, R. (2013). Saúde mental na atenção básica: a territorialização do cuidado. Porto Alegre: Sulina.

Spink, M. J. P. (2007). A Psicologia em diálogo com o SUS: prática profissional e produção acadêmica. São Paulo: Casa do Psicólogo. 